\title{
DIGITAL CERTIFICATE - OPPORTUNITY OR BARRIER IN THE RESTAURANT ACTIVITY? YOUNG PEOPLE'S OPINION ON THE FEELING OF HEALTH SAFETY IN PUBLIC EATING PLACES
}

\author{
Vlad Diaconescu ${ }^{1 *}$, Daniela-Elena Popescu ${ }^{2}$ \\ ${ }^{1}$ The Bucharest University of Economic Studies, Bucharest, Romania, diaconescuvlad17@stud.ase.ro \\ ${ }^{2}$ The Bucharest University of Economic Studies, Bucharest, Romania,popescudaniela17@stud.ase.ro
}

\begin{abstract}
Following the outbreak of the Covid-19 pandemic, several measures have been taken, in the hope of protecting human health and maintaining the economy and various industries at a functional level. One such measure was the introduction of the Covid-19 digital certificate for access to restaurants. This study aims to find out the opinion of young people about the feeling of health safety in public food establishments, as well as the opinion about the opportunity or barrier that arises from the use of the Covid-19 certificate. For this purpose, an online survey was conducted between October 14 and 20, 2021. For this study, university students and high school students were surveyed, the data being collected from 102 respondents, through a self-administered online questionnaire. The main objectives were to find out the level of knowledge of the Covid-19 digital certificate concept among young people, the feeling of health safety that the certificate generates among young people and the opinion about the opportunity or barrier that comes with its implementation. The results showed that all young people know the concept, but mainly tend to consider that the usage of the certificate doesn t generate an environment with an increased health safety in the restaurant or do not have an idea yet formed on this subject. More than two-thirds of the young people surveyed consider the certificate to be more of a barrier than an opportunity for the restaurant activity. At the same time, it turned out that girls are more skeptical than boys about the impact on health safety generated by the implementation of the certificate. The main limitation of this study is that the sample was small and unrepresentative, but nevertheless some interesting results were obtained.
\end{abstract}

Keywords:

Covid-19 digital certificate, restaurants, opportunity, barrier, health security

JEL Classification: $\mathrm{H} 12, \mathrm{I} 18, \mathrm{M} 10, \mathrm{Z} 38, \mathrm{Z39}$

DOI: $10.24818 / \mathrm{CTS} / 3 / 2021 / 2.07$

\section{Introduction}

The Covid-19 pandemic has caused multiple changes in people's lives, both personally and socially. Governments have had to implement certain social and economic policies in an attempt to reduce the community's transmission of the virus. One measure that has been implemented in many European Union countries, but not only, is the introduction of the Covid-19 digital certificate. Although the Covid19 digital certificate was originally introduced only to facilitate international travel, in an attempt to avoid multiple quarantines among travelers, over time, it has come to be used within states to gain access to various social places, including public eating places.

The Covid-19 pandemic has had a strong impact on the hospitality industry, forcing large-scale closure of establishments or the imposition of strict restaurant requirements due to the high risk of infection. The activity of restaurants depends on the customers, so the perception of individuals regarding the use of the digital certificate becomes a very important aspect. For this reason, restaurants are powerless to enforce the digital certificate, for it all depends on how people view this tool: either as an opportunity to return to normal or as a barrier.

This study aims to investigate the opinion of young people about the introduction of the Covid-19 digital certificate for access to restaurants and the feeling of health security generated by the conditioning of

* contact author 
access to public food establishments by the Covid-19 digital certificate. To this end, the paper continues with a literature review section, followed by research methodology and a section dedicated to research results.

\section{Literature Review}

During the health crisis generated by Covid-19, the restaurants had to go through a series of changes, so that their activity would not be completely stopped. New measures have been taken, such as: changing the way cleaning is done, adapting menus to reduce the number of foods served raw, cold or uncooked, switching from traditional paper to digital menus, changing the location of tables to keep the physical distance between customers, the placement of partitions between tables and other measures, depending on the evolution of the pandemic (Di et al., 2021).

In addition to the above-mentioned measures, the last decision of the governments regarding public eating places was to introduce the Covid-19 digital certificate attesting the recovery, vaccination or testing. The main stated objective of this measure was to revive the economy, giving restaurants the opportunity to operate as close as possible to the pre-pandemic conditions, but this largely depends on the decision of each people in part to get this digital certificate, many persons considering it as discriminatory. (Kosciejew, 2021).

Vergallo et al. (2021) states that the Covid-19 digital certificate guarantees equal freedom of movement to those who are vaccinated and those who cannot be vaccinated for health reasons, those who have not been vaccinated yet or those who do not want to. Specifically, those who refuse vaccination or testing have the alternative of quarantining or isolating for a specified period, and then being able to resume work normally. This solution may be fair in terms of travel, but for the entrance to the restaurant, the solution can no longer be applied, so the idea of inequality between those who have certificate and those who do not has reached again.

Perception of risk may vary by age. Younger people perceive a lower risk of the severe consequences of a possible illness, such as infectious diseases, which they understand to be controllable. Consequently, young people tend to behave riskier (Weinstein, 1982). Some research has shown that young adults and adolescents are less likely to comply with Covid-19 protection measures and public health guidelines. At the same time, this behavior can be determined by the characteristics of this segment of the population, because they have a lower acceptance of the rules, have a lower sense of guilt and lower self-control than older adults (Nivette et al., 2021). Older consumers are less likely to ignore the side effects of the disease and rely more on control measures to support their decisions. This may be related to the fact that the risk of Covid-19 is higher with age (Jin et al., 2020).

A study conducted in three countries on different continents (Europe, Africa, Asia) found that young Europeans are not very aware of the importance of measures to stop the spread of the Sars-Cov-2 virus (Seabra et al., 2021). Young people will probably not pay attention to the way restaurants change their operating rules to provide safety to their customers.

The digital certificate can be both an opportunity and a barrier to the activity of restaurants, as individuals are divided into two categories regarding the use of this type of document. There are both pros and cons. It is important that governments give citizens a chance to understand the usefulness of this document by using logical arguments. Therefore, the digital certificate would contribute to the activation and enforcement of public authority by placing people in a regime based on documents proving immunity at Covid-19 (Kosciejew, 2021).

\section{Research methodology}

This pilot research aims to find out the opinion of young people about the feeling of health safety in public eating places generated by the use of the Covid-19 digital certificate. During the research, the expression "public eating places" will be used, taking into account all the places where various dishes or drinks can be served. The notion of restaurants also refers to the same places.

It should be mentioned that the questions in the questionnaire did not relate to the actual use of the certificate at that time, in Romania. During the period in which the research was carried out, in Romania there was no possibility of testing in order to have access to restaurants, access being allowed only to 
the recovered or vaccinated persons. The questions referred to the situation in which the certificate would also include the possibility of testing, and its use in restaurants would not be mandatory, but would represent the choice of restaurant managers.

The main objectives of the research are: a) to find out the degree of knowledge among young people of the concept of Covid-19 digital certificate; b) the level of confidence among young people regarding the health safety offered by the use of the Covid-19 digital certificate for access to restaurants; c) the perception of young people regarding the use of the Covid-19 digital certificate as an opportunity or barrier in the activity of the restaurants.

The research method used was the survey. Data collection was done online through a questionnaire using Google Forms. The link that hosts the questionnaire was distributed to young people via Facebook, WhatsApp and Telegram. Data were collected between 14.10 and 20.10 2021, during which time 102 responses were recorded. The collected data was processed in Excel. The scale used was the 5-step Likert scale. Respondents are young people between the ages of 18 and 26. Among the young people surveyed, $88.2 \%$ of them are among the students from the Faculty of Business and Tourism and 11.8\% of the respondents are high school students.

Table no. 1: The sample structure

\begin{tabular}{|l|c|c|}
\hline 1. Place of provenance & \% & Number of respondents \\
\hline Urban & 75,5 & 77 \\
\hline Rural & 24,5 & 25 \\
\hline 2. Age & & 61 \\
\hline under 21 years old & 59,8 & 41 \\
\hline 21-26 years old & 40,2 & 24 \\
\hline 3. Gender & & 78 \\
\hline Male & 23,5 & \\
\hline Female & 76,5 & 12 \\
\hline 4. Studies level & & 72 \\
\hline High school & 11,8 & 18 \\
\hline Undergraduate & 70,6 & 35 \\
\hline Graduate & 17,6 & 67 \\
\hline 5. Employment status & & \\
\hline Yes & 34,3 & 59 \\
\hline No & 65,7 & 20 \\
\hline 6. Net monthly personal income & & 23 \\
\hline Less than 2000 lei & 57,8 & \\
\hline Between 2000 - 3000 lei & 19,6 & 4 \\
\hline More than 3000 lei & 22,5 & 98 \\
\hline 7. Working in a restaurant & & \\
\hline Yes & 3,9 & \\
\hline No & 96,1 & \\
\hline
\end{tabular}

Source: Author's own calculations

\section{Results and discussion}

The main results, according to the research objectives, are to be presented and analyzed in this section.

The first thing worth noting is that all the young people surveyed (100\%) were informed about the concept of digital certificate, although not all of them were put in a position to use it. Even if all respondents knew the concept, it is interesting that $6.9 \%$ of them did not know how to obtain the certificate. With a majority of over $80 \%$, the young people surveyed replied that using the certificate seemed easy to them.

When asked if they consider the use of the Covid-19 digital certificate for access to restaurants to be discriminatory, $52 \%$ of young people answered "Yes", with the rest (48\%) saying "No". It should be 
noted that the question was based on the possibility of obtaining the Covid-19 digital certificate by testing and its use would not be required by law but only represents the option of restaurant managers.

Table no. 2: Opinion on the discriminatory nature of the digital certificate, depending on the age of the respondents $(\%)$

\begin{tabular}{|l|c|c|c|}
\hline Age & Yes & No & Total \\
\hline under 21 years old & 47.54 & 52.46 & 100.00 \\
\hline 21-26 years old & 58.54 & 41.46 & 100.00 \\
\hline Total & $\mathbf{5 1 . 9 6}$ & $\mathbf{4 8 . 0 4}$ & $\mathbf{1 0 0 . 0 0}$ \\
\hline
\end{tabular}

Source: Author's own calculations

The data in table no. 2 shows that along with the age, young people consider that the use of the digital certificate for access to restaurants is rather discriminatory.

Table no. 3: Opinion on the discriminatory nature of the certificate, depending on gender (\%)

\begin{tabular}{|l|c|c|c|}
\hline Gender & Yes & No & Total \\
\hline Male & 33.33 & 66.67 & 100.00 \\
\hline Female & 57.69 & 42.31 & 100.00 \\
\hline Total & $\mathbf{5 1 . 9 6}$ & $\mathbf{4 8 . 0 4}$ & $\mathbf{1 0 0 . 0 0}$ \\
\hline
\end{tabular}

Source: Author's own calculations

It is observed that women consider to a greater extent than men that the imposition of the digital certificate for access to restaurants is rather discriminatory.

According to fig. no. 1 it can be stated that over $42 \%$ of young people surveyed are not convinced that the certificate provides health safety in restaurants, and about $28 \%$ do not have a strong opinion about the health safety provided by the usage of the digital certificate. The average of the answers is 2.7 on a scale of 1 to 5, with the meaning: 1 - does not provide security at all, 5 - provides high security. Young people tend to believe more that the usage of the certificate does not provide increased health safety in restaurants.

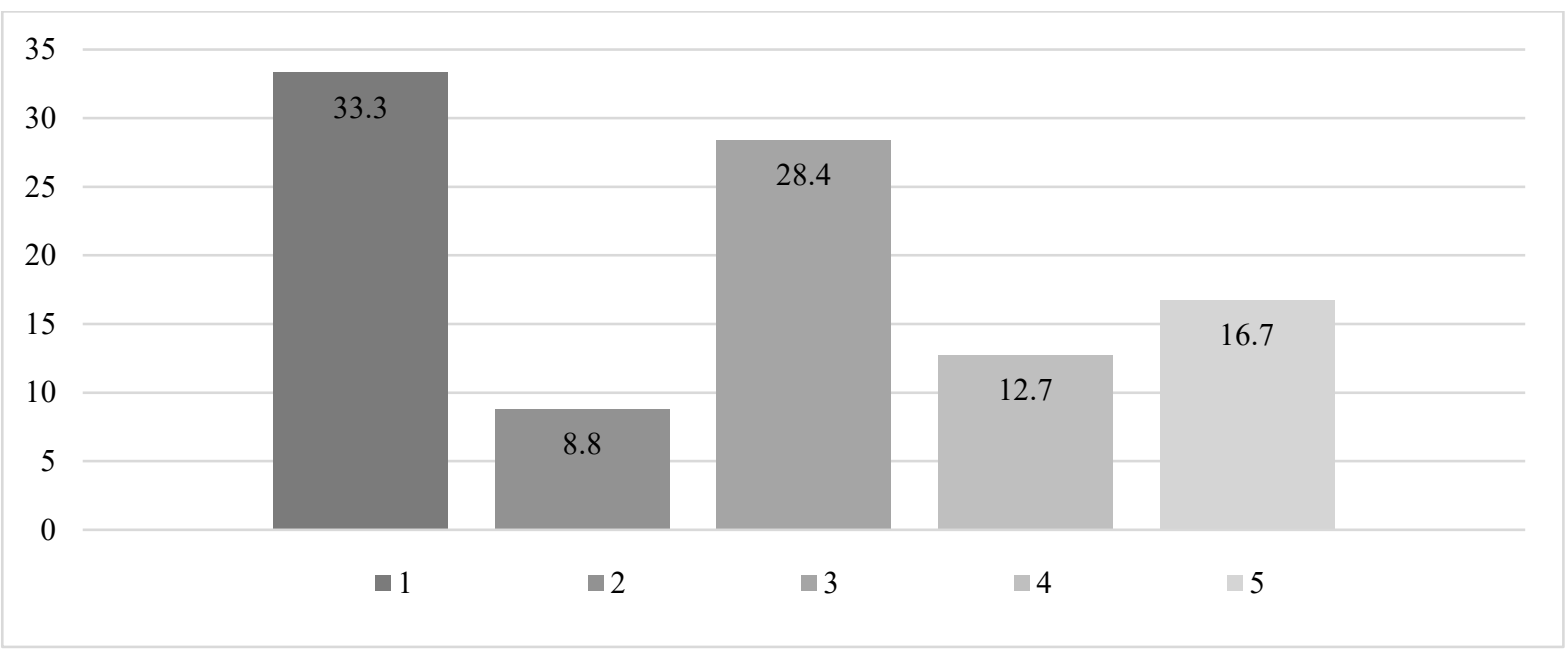

Fig. no. 1: Young people's opinion regarding the health safety based on the use of the certificate for access to restaurants ( 1 - does not offer safety at all, 5 - offers high safety)

Source: Author's own calculations

In order to have a more detailed look at the considerations presented above, a pivot table by gender was made, in order to see how the opinions are divided (1- no safety at all: 5- high safety).

Table no. 4: Opinion on health safety induced by digital certificate by gender (\%)

\begin{tabular}{|l|c|c|c|c|c|c|}
\hline Gender & $\mathbf{1}$ & $\mathbf{2}$ & $\mathbf{3}$ & $\mathbf{4}$ & $\mathbf{5}$ & Total \\
\hline
\end{tabular}




\begin{tabular}{|l|l|l|l|l|l|l|}
\hline Male & 29.17 & 8.33 & 20.83 & 16.67 & 25.00 & 100.00 \\
\hline Female & 34.62 & 8.97 & 30.77 & 11.54 & 14.10 & 100.00 \\
\hline Total & $\mathbf{3 3 . 3 3}$ & $\mathbf{8 . 8 2}$ & $\mathbf{2 8 . 4 3}$ & $\mathbf{1 2 . 7 5}$ & $\mathbf{1 6 . 6 7}$ & $\mathbf{1 0 0 . 0 0}$ \\
\hline
\end{tabular}

Source: Author's own calculations

Thus, a more detailed analysis (table no.4) shows that girls are more skeptical than boys about the health safety provided by using the certificate for acces in restaurants, which is also found in the case of the opinion on the discriminatory nature of access conditioning in restaurants by the existence of the digital certificate.

Table no. 5 shows that, regardless of the age group, young people who consider the usage of the certificate to be a discriminatory one would choose in proportion of over $90 \%$ a restaurant that would not condition access to the existence of the certificate, the reverse situation being equally obvious.

Table no. 5: Link between age, opinion on discrimination and the choice of restaurant (\%)

\begin{tabular}{|l|c|c|c|}
\hline \multirow{2}{*}{ Age/ Opinion on discrimination (Yes, No) } & \multicolumn{2}{|c|}{ Restaurant access } & \\
\cline { 2 - 4 } & $\begin{array}{c}\text { With } \\
\text { certificate }\end{array}$ & $\begin{array}{c}\text { Without } \\
\text { certificate }\end{array}$ & Total \\
\hline under 21 years old & $\mathbf{4 9 . 1 8}$ & $\mathbf{5 0 . 8 2}$ & $\mathbf{1 0 0 . 0 0}$ \\
\hline Yes & 3.45 & 96.55 & 100.00 \\
\hline No & 90.63 & 9.38 & 100.00 \\
\hline $\mathbf{2 1 - 2 6}$ years old & $\mathbf{3 9 . 0 2}$ & $\mathbf{6 0 . 9 8}$ & $\mathbf{1 0 0 . 0 0}$ \\
\hline Yes & 8.33 & 91.67 & 100.00 \\
\hline No & 82.35 & 17.65 & 100.00 \\
\hline Total & $\mathbf{4 5 . 1 0}$ & $\mathbf{5 4 . 9 0}$ & $\mathbf{1 0 0 . 0 0}$ \\
\hline
\end{tabular}

Source: Author's own calculations

The data in table no. 5 related to the choice of restaurant according to the application of the Covid-19 digital certificate appear to be in line with the data in the table no. 2 , which shows the perception of discriminatory nature according to age.

Therefore, most young people surveyed would tend to choose a restaurant that does not require the presentation of a digital certificate. When respondents were asked how annoyed they would be to go to a restaurant that requires this digital certificate, the answers are polarized (fig. no.2).

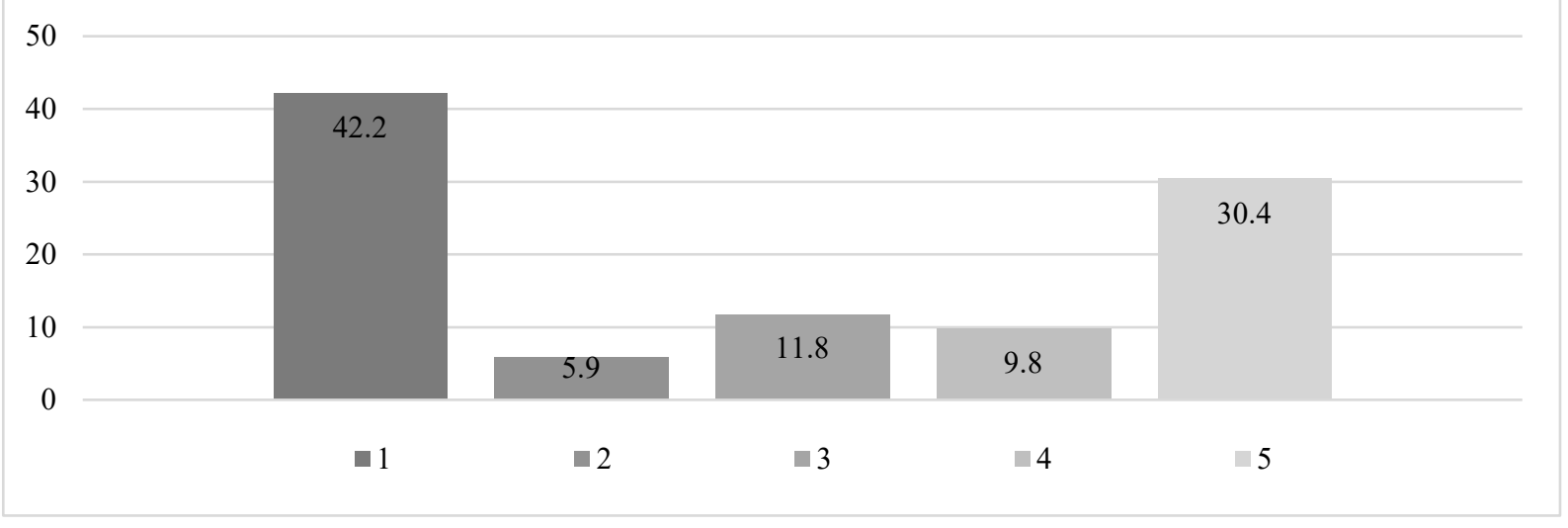

Fig. no. 2 On a scale of 1 to 5 (1 - not bothered at all, 5 - very upset) how annoyed would you be to go to a restaurant that requires a digital certificate?

Source: Author's own calculations

Of the total responses, $48.1 \%$ said they would not be bothered at all, or would be very little bothered, while $40.2 \%$ said they would be bothered and very bothered to go to a restaurant requesting the digital certificate.

If most young people tend to believe that the digital certificate does not provide increased health safety in restaurants (Fig. no. 1), according to table no. 6, it turns out that about $39 \%$ of young people would feel safe in a restaurant that would not require the presentation of the digital certificate, and about $32 \%$ would feel neither safe nor insecure. 
Table no. 6: Link between gender and the safety feeling when visiting a restaurant that does not request the digital certificate $(\%)$

\begin{tabular}{|l|c|c|c|c|c|c|}
\hline & Very unsafe & & & & Very safe & \\
\hline Gender & $\mathbf{1}$ & $\mathbf{2}$ & $\mathbf{3}$ & $\mathbf{4}$ & $\mathbf{5}$ & Total \\
\hline Male & 16.67 & 25.00 & 25.00 & 8.33 & 25.00 & 100.00 \\
\hline Female & 12.82 & 11.54 & 34.62 & 20.51 & 20.51 & 100.00 \\
\hline Total & $\mathbf{1 3 . 7 3}$ & $\mathbf{1 4 . 7 1}$ & $\mathbf{3 2 . 3 5}$ & $\mathbf{1 7 . 6 5}$ & $\mathbf{2 1 . 5 7}$ & $\mathbf{1 0 0 . 0 0}$ \\
\hline
\end{tabular}

Source: Author's own calculations

A more detailed analysis (table no. 6) shows that men tend to feel less safe than girls in such a situation.

Therefore, girls consider, to a greater extent than boys, that the digital certificate is discriminatory, that it does not bring increased health security and at the same time they would feel safe in a restaurant that does not require a certificate.

Table no. 7: Link between place of provenance and the safety feeling when visiting a restaurant that does not request the digital certificate $(\%)$

\begin{tabular}{|l|c|c|c|c|c|c|}
\hline & Very unsafe & & & & Very safe & \\
\hline Place of provenance & $\mathbf{1}$ & $\mathbf{2}$ & $\mathbf{3}$ & $\mathbf{4}$ & $\mathbf{5}$ & Total \\
\hline Rural & 8.00 & 28.00 & 36.00 & 12.00 & 16.00 & 100.00 \\
\hline Urban & 15.58 & 10.39 & 31.17 & 19.48 & 23.38 & 100.00 \\
\hline Total & $\mathbf{1 3 . 7 3}$ & $\mathbf{1 4 . 7 1}$ & $\mathbf{3 2 . 3 5}$ & $\mathbf{1 7 . 6 5}$ & $\mathbf{2 1 . 5 7}$ & $\mathbf{1 0 0 . 0 0}$ \\
\hline
\end{tabular}

Source: Author's own calculations

Table no. 7 shows that young people from rural areas, compared to those from urban areas, seem to feel more insecure in terms of health security in a restaurant that does not condition the access to the digital certificate.

Therefore, the percentage of those who would feel safe in a restaurant where access is without the digital certificate $(39.2 \%)$ is comparable to that of young people $(42.1 \%)$ who consider that the certificate does not provide security at all or almost not at all. These percentages also seem to be in line with the percentage of young people who say they would be bothered and very bothered to go to a restaurant that requires the digital certificate $(40.2 \%)$.

It can be concluded that there is a constant percentage of young people (about $40 \%$ ) who do not believe in the usefulness of the Covid-19 digital certificate to increase health safety in restaurants and who are even bothered by the idea of having conditioned access by this type of certificate.

Another idea resulting from the research is that the majority (70.6\%) of young people consider that the certificate is in fact a barrier in the activity of restaurants.

Table no. 8: Link between gender and respondent's opinion regarding the opportunity/barrier of certificate usage (\%)

\begin{tabular}{|l|c|c|c|}
\hline Gender & Barrier & Opportunity & Total \\
\hline Male & 62.50 & 37.50 & 100.00 \\
\hline Female & 73.08 & 26.92 & 100.00 \\
\hline Total & $\mathbf{7 0 . 5 9}$ & $\mathbf{2 9 . 4 1}$ & $\mathbf{1 0 0 . 0 0}$ \\
\hline
\end{tabular}

Source: Author's own calculations

A detailed analysis by gender (table no. 8) shows that women are more likely than men to consider the use of the Covid-19 digital certificate for access to restaurants as a barrier for the restaurants activity. Women also considered more than men that the certificate does not bring increased health security. 
Table no. 9: Link between age/place of provenance/work in the industry and respondent's opinion regarding the opportunity/barrier of certificate usage $(\%)$

\begin{tabular}{|l|c|c|c|}
\hline Age & Barrier & Opportunity & Total \\
\hline under 21 years ols & 70.49 & 29.51 & 100.00 \\
\hline 21-26 years old & 70.73 & 29.27 & 100.00 \\
\hline Place of provenance & & & \\
\hline Rural & 72.00 & 28.00 & 100.00 \\
\hline Urban & 70.13 & 29.87 & 100.00 \\
\hline Working in a restaurant & & & \\
\hline Yes & 75.00 & 25.00 & 100.00 \\
\hline No & 70.41 & 29.59 & 100.00 \\
\hline Total & $\mathbf{7 0 . 5 9}$ & $\mathbf{2 9 . 4 1}$ & $\mathbf{1 0 0 . 0 0}$ \\
\hline
\end{tabular}

Source: Author's own calculations

Regardless of age or place of provenance, over $70 \%$ of young people consider the certificate to be a barrier for restaurant activity. An interesting aspect according to table no. 9 is that young people who work in a restaurant tend to consider the certificate to be a barrier more than those young people who do not work in a restaurant. Even if the difference is small, it is interesting that those who work in the field perceive the certificate as a barrier in carrying out the activity.

Table no.10: Link between gender and opinion on level of the opportunity of certificate usage (\%)

\begin{tabular}{|l|c|c|c|c|c|c|}
\hline & Totally inopportune & & & & Totally opportune & \\
\hline Gender & $\mathbf{1}$ & $\mathbf{2}$ & $\mathbf{3}$ & $\mathbf{4}$ & $\mathbf{5}$ & Total \\
\hline Male & 33.33 & 0.00 & 33.33 & 12.50 & 20.83 & 100.00 \\
\hline Female & 38.46 & 11.54 & 34.62 & 8.97 & 6.41 & 100.00 \\
\hline Total & $\mathbf{3 7 . 2 5}$ & $\mathbf{8 . 8 2}$ & $\mathbf{3 4 . 3 1}$ & $\mathbf{9 . 8 0}$ & $\mathbf{9 . 8 0}$ & $\mathbf{1 0 0 . 0 0}$ \\
\hline
\end{tabular}

Source: Author's own calculations

Of the young people surveyed, $46.1 \%$ consider the use of the digital certificate totally or almost totally inappropriate for the performance of restaurants. Others, representing $34.3 \%$, do not have a clear opinion on the appropriateness of using the certificate (table no. 10). Thus, it can be said that only $20 \%$ of young people perceive the use of the certificate as an opportunity for restaurant performance.

Among the respondents, $63.7 \%$ consider that the barrier brought by the certificate is a big and very big one, while $21.6 \%$ do not have a clear opinion. Only $15 \%$ consider that the certificate is not a barrier to the activity (table no. 11).

Thus, it results in a percentage of $15-20 \%$ of young people who not only do not see the certificate as a barrier, but they consider it an opportunity for restaurants activity.

Table no. 11: Link between gender and opinion on level of the barrier of certificate usage (\%)

\begin{tabular}{|l|c|c|c|c|c|c|}
\hline & Not a barrier at all & & & & Very important barrier & \\
\hline Gender & $\mathbf{1}$ & $\mathbf{2}$ & $\mathbf{3}$ & $\mathbf{4}$ & $\mathbf{5}$ & Total \\
\hline Male & 16.67 & 4.17 & 29.17 & 8.33 & 41.67 & 100.00 \\
\hline Female & 7.69 & 5.13 & 19.23 & 23.08 & 44.87 & 100.00 \\
\hline Total & $\mathbf{9 . 8 0}$ & $\mathbf{4 . 9 0}$ & $\mathbf{2 1 . 5 7}$ & $\mathbf{1 9 . 6 1}$ & $\mathbf{4 4 . 1 2}$ & $\mathbf{1 0 0 . 0 0}$ \\
\hline
\end{tabular}

Source: Author's own calculations

According to table no. 11 men answered in a proportion of $20 \%$ that the certificate is not or is a very small barrier in the activity of restaurants, and $30 \%$ of them do not yet have an opinion on this issue. On the other hand, $68 \%$ of women said that the digital certificate is a big and very big barrier.

Thus, it can be said that women have a stronger belief than men that the Covid-19 digital certificate is in fact a barrier for restaurants. This percentage is in line with the above results where women generally see the digital certificate as a barrier and they also considered more than men that the certificate does not bring increased health safety. 


\section{Conclusions and limitations}

The Covid-19 pandemic has led to major changes in several industries, changes that have required decision-making in order to reduce the negative impact on activities, while also trying to protect human health. Some industries, such as the public eating places, have suffered more than others in terms of the way they operate. All the measures taken, from the reduction of the number of seats that can be occupied in a room, to the digitization of menus and the installation of dividing walls between tables, all these have greatly affected people's experience in restaurants and their well-being in general.

The measure that has caused a major controversy is the introduction of the Covid-19 digital certificate for access to restaurants. Although it was promoted as a chance for managers and clients to return to normal, the reality has shown that opinions are divided.

Following this study, which investigated the opinion of young people about the introduction of the Covid-19 digital certificate, several interesting aspects emerged.

First of all, all the young people know what this concept means and half of them consider it discriminatory. A more detailed analysis showed that women consider the certificate to be discriminatory more than men do. It should be noted that the research was conducted under the assumption that the digital certificate is not mandatory for access to restaurants, but would represent the choice of each unit whether to request it or not; at the same time, people can get their digital certificate by testing. At the time of data collection, in Romania, there was no possibility to obtain the Covid-19 digital certificate by testing.

Young people tend to think that the certificate does not come with increased health safety in restaurants, women being more skeptical than men in this regard as well.

In the debate on the opportunity/barrier brought by the usage of the Covid-19 digital certificate for the activity of restaurants, young people consider, in proportion of $70 \%$, that the certificate is a barrier for the activity of restaurants, and of these, $64 \%$ consider it to be a big and a very big barrier. And in this regard, women consider more than men that the certificate is more a barrier than an opportunity for restaurants. Thus, it can be said that women are generally more skeptical, in all respects, about the usage of the Covid-19 digital certificate for restaurants.

The main limitation of this study is the small sample, the study being a pilot survey. The research should be carried out on a representative sample from Romania. Being a pilot survey with a small sample, the statistical interpretations are unrepresentative, being made with some basic functions in Excel.

\section{References}

Di, W., Jun, Y., and Brett, A.S.M., 2021. The effects of crowdedness and safety measures on restaurant patronage choices and perceptions in the COVID-19 pandemic. International Journal of Hospitality Management, [e-journal] 95,1-10. https://doi.org/10.1016/j.ijhm.2021.102910

Jin, J.M., Bai, P., He, W., Wu, F., Liu, X.F., Han, D.M., Liu, S., and Yang, J.K., 2020. Gender Differences in Patients With COVID-19: Focus on Severity and Mortality. Frontiers in Public Health, [e-journal] 8:152. https://doi.org/10.3389/fpubh.2020.00152

Kosciejew, M.R.H., 2021. COVID-19 immunity (or vaccine) passports: a documentary overview and analysis of regimes of health verification within the coronavirus pandemic. Journal of Documentation, [e-journal] vol. ahead-of-print. https://doi.org/10.1108/JD-04-2021-0079

Nivette, A., Ribeaud, D., Murray, A., Steinhoff, A., Bechtiger, L., Hepp, U., Shanahan, L., and Eisner M., 2021. Non-compliance with COVID-19-related public health measures among young adults in Switzerland: Insights from a longitudinal cohort study. Social Science \& Medicine, [e-journal] 268:113370. https://doi.org/10.1016/j.socscimed.2020.113370

Park, C.L., Russell, B.S., Fendrich, M., Finkelstein-Fox, L., Hutchison, M., and Becker, J., 2020. Americans' COVID-19 Stress, Coping, and Adherence to CDC Guidelines. Journal of General Internal Medicine, [e-journal] 35(8):2296-2303. https://doi.org/10.1007/s11606-020-05898-9

Seabra, C., AlAshry, M., Çınar, K., Raja, I., Reis, M., and Sadiq, N., 2021. Restrictions' acceptance and risk perception by young generations in a COVID-19 context. International Journal of Tourism Cities, [e-journal] vol. 7, no. 2, pp. 463-491. https://doi.org/10.1108/IJTC-08-2020-0165 
Vergallo, G.M., Zaami, S., Negro, F., Brunetti, P., Del Rio, A., and Marinelli, E., 2021. Does the EU COVID Digital Certificate Strike a Reasonable Balance between Mobility Needs and Public Health? Medicina, [e-journal] 57, 1077. https://doi.org/10.3390/medicina57101077

Webster, R.K., Brooks, S.K., Smith, L.E., Woodland, L., Wessely, S., and Rubin, G.J., 2020. How to improve adherence with quarantine: Rapid review of the evidence. Public Health, [e-journal] 182:163-169. https://doi.org/10.1016/j.puhe.2020.03.007

Weinstein, N.D., 1982. Unrealistic Optimism About Susceptibility to Health-Problems. Journal of Behavioral Medicine, [e-journal] 5(4):441-460. https://doi.org/10.1007/BF00845372 